\title{
Tyrosine Hydroxylase Expression in Differentiating Neurons of the Rat Arcuate Nucleus: Stimulatory Influence of Serotonin Afferents
}

\author{
Viktoria I. Melnikova, ${ }^{1}$ Michael V. Ugrumov, ${ }^{1,2}$ Evgenia V. Proshlyakova, ${ }^{1}$ \\ André Calas, ${ }^{3}$ and Jean Thibault ${ }^{4}$ \\ ${ }^{\prime}$ Laboratory of Hormonal Regulations, Institute of Developmental Biology and ${ }^{2}$ Laboratory of \\ Neurohistology, Institute of Normal Physiology, Russian Academy of Medical Sciences, Moscow, Russia; \\ ${ }^{3}$ Département des Signaux Intercellulaires, Institut des Neurosciences, Université P. et M. Curie, Paris, \\ France; ${ }^{+}$Laboratoire de Neurobiologie Moléculaire, Université Paris, Créteil; France
}

\begin{abstract}
The influence of serotonin afferents on tyrosine hydroxylase expression in differentiating neurons of the rat arcuate nucleus was studied in vivo and in vitro. In the in vivo study, pchlorophenylalanine inhibited serotonin synthesis in fetal brain from the $11^{\text {th }}$ to the $20^{\text {th }}$ embryonic day. We then used semiquantitative immunocytochemistry to evaluate tyrosine hydroxylase levels in neurons of the arcuate nucleus in fetuses at the $21^{\text {st }}$ embryonic day or in offspring at the $35^{\text {th }}$ postnatal day. Serotonin depletion significantly decreased the tyrosine hydroxylase content in neurons of males and females at the $21^{\text {st }}$ embryonic day and in males at the $35^{\text {th }}$ postnatal day. For the in vitro study, embryonic neurons of the arcuate nucleus were cocultured with embryonic neurons of the raphe nucleus, the main source of serotonin innervation of the brain, including the arcuate nucleus. Co-culture of the neurons resulted in a genderspecific increase of the tyrosine hydroxylase level in the neurons of the arcuate nucleus. In
\end{abstract}

Reprint request to: Prof. Michael V. Ugrumov., Institute of Developmental Biology, Russian Academy of Sciences, 26 Vavilov St., Moscow 117808, Russia. e-mail: mikhael-ugrumov@mail.ru turn, the neurons of the raphe nucleus showed increased levels of serotonin in both males and females, with no sexual dimorphism. Thus, our results suggest a stimulatory, long-lasting effect of serotonin afferents on tyrosine hydroxylase expression in the differentiating neurons of the rat arcuate nucleus during prenatal ontogenesis.

\section{KEYWORDS}

development, immunocytochemistry, raphe nucleus, hypothalamus

\section{INTRODUCTION}

Since the initial detection of dopamine in neurons of the arcuate nucleus and their axon terminals in the median eminence with the histofluorescence technique (Dahlström \& Fuxe, 1964; Fuxe, 1964; Björklund \& Nobin, 1973), the socalled tuberoinfundibular dopaminergic system has attracted the particular attention of neurobiologists and neuroendocrinologists. This interest is explained by the great contribution of the tuberoinfundibular dopaminergic system to the inhibitory control of the adenohypophysial prolactin secretion and, thereby, to the regulation of reproduction (Neill, 1988). In 
turn, in adults, the dopaminergic neurons of the arcuate nucleus are under complex regulation by intercellular signals like prolactin, estrogens, testosterone, serotonin, enkephalin, galanin, neuropeptide Y (Moore et al., 1985; Kiss \& Halász, 1986; Arbogast \& Voogt, 1991, 1993; Hrabovszky \& Liposits, 1994; Magoul et al., 1994; Hong et al., 1995). Arbogast and Voogt suggested that the same intercellular messengers might influence the differentiation of dopaminergic neurons of the arcuate nucleus during ontogenesis. Although the genesis and differentiation of dopaminergic neurons in the arcuate nucleus have been studied in many species (Halpern-Sebold et al., 1985; Daikoku et al., 1986; Friedman et al., 1989; Ugrumov et al., 1989; Richards et al., 1990; Romero \& Phelps, 1993; Phelps et al., 1994; Balan et al., 1996, 2000), few data are available on their regulation by intercellular signals (Friedman et al., 1989; Romero \& Phelps, 1993; Phelps et al., 1994). The aim of the present study was to evaluate the possible influence of serotonin afferents on differentiating dopaminergic neurons of the arcuate nucleus; namely, on the expression of tyrosine hydroxylase (TH), the first, rate-limiting enzyme of dopamine synthesis. Serotonin afferents appear to be among the potential regulators of the differentiation of dopaminergic neurons as

1. dopaminergic neurons in adults display serotonin receptors and are synaptically innervated by serotonin fibers belonging to the neurons of the raphe nucleus (Fuller \& Clemens, 1981; Steinbusch \& Nieuwenhuys, 1981; Kiss \& Halász, 1986; Willoughby et al., 1988; Jorgensen et al., 1993);

2. serotonin is generally considered a putative morphogen that is functionally active before synaptogenesis and the onset of neurotransmission (Lauder et al., 1980; Lauder, 1983, 1990; Ugrumov et al., 1994; Ugrumov, 1997); and
3. there is at least a timing correlation between the early differentiation of dopaminergic neurons (Daikoku et al., 1986; Ugrumov et al., 1989; Balan et al., 1996, 2000) and the initial arrival of serotonin fibers in the arcuate nucleus (Lidov \& Molliver, 1982; Aitken \& Tork, 1988).

\section{EXPERIMENTAL METHODS}

\section{Pharmacological model of serotonin depletion}

Wistar pregnant rats were injected intraperitoneally daily with pCPA in saline $(100 \mathrm{mg} / \mathrm{kg} \mathrm{b}$. wt.), an inhibitor of serotonin synthesis, from $\mathrm{d} 11$ to $d 20$ of pregnancy (day of conception being the first embryonic day; E1). Untreated control animals received saline over the same period. Pregnant rats on $d 21$ of gestation or their offspring on postnatal d 35 (the day of parturition being the first postnatal day; P1) were anesthetized with pentobarbital (50 $\mathrm{mg} / \mathrm{kg} \mathrm{b}$. wt.); the fetuses were removed for subsequent processing. On E21, a minimum of four treated males and four untreated control males and the same number of females from two pregnant rats were processed for immunocytochemistry. The same number of pCPA-treated and control males and females at P35 were used from a minimum of two litters.

\section{Fixation and immunocytochemistry}

All reagents were from Sigma unless otherwise noted. The fetuses and young rats were perfused through the heart, first with saline for 2 to $5 \mathrm{~min}$ at $37^{\circ} \mathrm{C}$ and then fixed for $15 \mathrm{~min}$ with $4 \%$ paraformaldehyde in $0.1 \mathrm{M}$ sodium phosphate buffer, $\mathrm{pH} 7.4$, at $4{ }^{\circ} \mathrm{C}$. The brain was then postfixed for $2 \mathrm{~h}$ by immersion in paraformaldehyde at $4{ }^{\circ} \mathrm{C}$, rinsed for $1 \mathrm{~h}$ in $0.02 \mathrm{M}$ phosphate 
buffer and $0.9 \% \mathrm{NaCl}(\mathrm{PBS}), \mathrm{pH} 7.2-7.4$, at $4{ }^{\circ} \mathrm{C}$, immersed overnight in $15 \%$ sucrose PBS at $4^{\circ} \mathrm{C}$; and then frozen in isopentane at $-35^{\circ} \mathrm{C}$. Serial coronal sections of the mediobasal hypothalamus (arcuate nucleus and median eminence) were cut into $12-\mu \mathrm{m}$-thick sections with a cryostat microtome at $-20{ }^{\circ} \mathrm{C}$, thaw-mounted on slides covered with gelatine, and quickly dried on a slide warmer. Sections of the brains from pCPA-treated and control males and females of the same age were mounted on the same slide and processed together.

We used the avidin-biotin technique (Bayer et al., 1979) for immunostaining studies. Normal serum, primary, and secondary antibodies were diluted in PBS with $0.1 \%$ Triton X-100. The sections were incubated successively with the following:

1. $0.3 \% \mathrm{H}_{2} \mathrm{O}_{2}, 30 \mathrm{~min}$ at room temperature;

2. $1 \%$ normal goat serum and $0.1 \%$ Triton $\mathrm{X}-100$, $30 \mathrm{~min}$ at room temperature;

3. primary rabbit anti-TH antibodies (dil 1:3,000), overnight at $4{ }^{\circ} \mathrm{C}$;

4. goat anti-rabbit-biotinylated secondary antibody (dil 1:200), $2 \mathrm{~h}$ at room temperature; and

5. avidin biotin complex (dil 1:200), $1 \mathrm{~h}$ at room temperature.

The specificity of the antiserum raised against TH was controlled for by Arluison et al. (1984) and in the present study by omitting the primary antibody. After each incubation (except the second), the sections were rinsed with PBS. All incubations were carried out in a humid chamber. The sections were rinsed with $0.05 \mathrm{M}$ Tris- $\mathrm{HCl}$ buffer, $\mathrm{pH}$ 7.6; the peroxidase reaction of the avidin-biotin complex was developed in Tris- $\mathrm{HCl}$ buffer containing $0.05 \%$ 3,3'-diaminobenzidine tetrahydrochloride and $0.01 \%$ hydrogen peroxide. The developing time was constant for each age studied. Finally, the sections were dehydrated and coverslipped.

\section{Dissociated primary culture}

At the $17^{\text {th }}$ day of gestation, the pregnant rats were decapitated, and the fetuses were removed aseptically. Gender was determined by revision of the gonads, and male and female materials were processed separately. The fetuses were decapitated, and the brain was removed from the skull. The central rhombencephalon with the raphe nucleus was dissected using mesencephalic and cervical flexures as landmarks (Konig et al., 1987). The wedge of tissue was removed just caudal to the mesencephalic flexure (rostral to the rhombencephalic isthmus). For dissection of the mediobasal hypothalamus, the brain was placed on its dorsal surface, and frontal cuts were made just caudal to the pituitary stalk and rostral to the primary portal plexus. Finally, the hypothalamic area around the bottom of the third ventricle was dissected from the thick frontal slice, and the meninges were removed (Melnikova et al., 1999).

The dissected tissues were used to prepare dissociated primary cultures as described before (Melnikova et al., 1999; Tixier-Vidal \& FaivreBauman, 1990). For this purpose, mediobasal hypothalamus and raphe nucleus from males and females were pooled separately and dissociated mechanically in F12/DMEM medium (Gibco), supplemented with $10 \%$ fetal calf serum. The cell suspension was centrifuged for $10 \mathrm{~min}$ at $800 \mathrm{rpm}$ and then resuspended in serum-free F12/DMEM containing transferrin $(100 \mu \mathrm{g} / \mathrm{mL})$, putrescin $\left(10^{-4} \mathrm{M}\right)$, insulin $(5 \mu \mathrm{g} / \mathrm{mL})$, glutamine $\left(5 \times 10^{-3} \mathrm{M}\right)$, sodium selenite $\left(2 \times 10^{-5} \mathrm{M}\right)$, progesterone $\left(2 \times 10^{-8} \mathrm{M}\right), 17-\beta$-estradiol $\left(10^{-12} \mathrm{M}\right)$, corticosterone $\left(10^{-7} \mathrm{M}\right)$, triiodothyronine $\left(10^{-8} \mathrm{M}\right)$, HEPES $(3.57 \mathrm{~g} / \mathrm{L})$, sodium bicarbonate $(2.44 \mathrm{~g} / \mathrm{L})$ plus arachidonic acid $(1 \mu \mathrm{g} / \mathrm{mL})$, and docosahexaenoic acid $(0.5 \mu \mathrm{g} / \mathrm{mL})$, adsorbed on bovine serum albumin (fatty acid free, $37.5 \mu \mathrm{g}$ / $\mathrm{mL}$ ). The cell suspension, at a density of 500,000 cells $/ \mathrm{cm}^{2}$, was placed onto poly-L-lysine-coated 22 - 
$\mathrm{mm}$ plastic coverslips in $60-\mathrm{mm}$ diameter Petri dishes ( 2 coverslips per dish). Cell suspensions from the mediobasal hypothalamus and the raphe nucleus were plated on separate coverslips. The coverslips with mediobasal hypothalamus and raphe nucleus were placed into the same Petri dish for co-culture and into different Petri dishes for single cultures. The cell survival in the primary cell suspension usually exceeded $85 \%$, estimated by trypan blue exclusion in a hemocytometer. All procedures described above were made in sterile conditions.

The cultures were maintained for $7 \mathrm{~d}$ at $37^{\circ} \mathrm{C}$ in a humidified atmosphere of $5 \% \mathrm{CO}_{2}$. The incubation medium supplemented with cytosine arabinoside $\left(10^{-8} \mathrm{M}\right)$, an inhibitor of glial cell proliferation, was renewed on the $3^{\text {rd }}$ and $5^{\text {th }}$ days. On the $7^{\text {th }}$ day, the cultures were fixed for $15 \mathrm{~min}$ with $4 \%$ paraformaldehyde in $0.1 \mathrm{M}$ PBS ( $\mathrm{pH} 7.4$ ) at room temperature and then rinsed with $0.02 \mathrm{M}$ PBS. Cultures of mediobasal hypothalamus and raphe nucleus were then immunostained for $\mathrm{TH}$ or for serotonin, respectively, using the avidin-biotin technique, as described for the cryostat sections, but with $4 \%$ normal goat serum replacing the $1 \%$ serum. Antiserum to serotonin was diluted 1:2000. The specificity of the antiserum was controlled for by Tramu et al. (1983) and in this study by omitting the primary antibody.

\section{Semi-quantitative image analysis}

Carto, ${ }^{(3)}$ a software program developed by IMSTAR (France), was used for the semiquantitative analysis of TH-immunoreactive material in the cell bodies of the arcuate nucleus at E21 and P35, as well as of serotonin and TH-immunoreactive materials in culture and co-culture of the mediobasal hypothalamus and raphe nucleus. Using this approach, we could accurately assess relative amounts of substrates and easily compare the results of different experiments. Indeed, all preparative procedures of the sections and cultures were performed under standardized conditions, allowing meaningful quantitative analysis (Smolen, 1990). Each section or culture was reviewed under a light microscope with $\mathrm{a} \times 25$ objective, followed by the transfer of its images through a video camera (CCD) to a computer monitor (Pentium 60; IBM, Armonk, NY, USA) and subsequent recording.

The profiles of the individual immunoreactive cell bodies were outlined with a light pen to get a morphometric mask, and the relative amounts of immunoreactive materials were measured as 'gray level' (GL) and related to the optical density (OD) of the specimen as follows (Smolen, 1990):

$\mathrm{OD}_{\text {Specimen }}-\mathrm{OD}_{\text {Background }}=\log \left(\mathrm{GL}_{\text {Background }}\right)-\log \left(\mathrm{GL}_{\text {Specimen }}\right)$.

The GL of the background was measured in the vicinity of the mediobasal hypothalamus with no specific immunostaining on sections or in the immunonegative areas in culture.

\section{$\left[{ }^{3} \mathbf{H}\right]$ Serotonin uptake}

The hypothalamus with the adjacent septum and diagonal band, corresponding to neuroendocrine centers with an important serotonin innervation (Steinbusch \& Nieuwenhuys, 1981; Montange \& Calas, 1988), was dissected in 21-d-old fetuses treated with pCPA or saline, as described above. As gender differences have not been found in the serotonin system of rat fetuses (Lidov \& Molliver, 1982; Wallace \& Lauder, 1983), we evaluated male and female nervous tissues together. Tissue fragments were incubated in Krebs-Ringer bicarbonate medium $(\mathrm{pH} 7.4)$ composed of $(\mathrm{mM}): \mathrm{NaCl}$ (120), $\mathrm{KCl}$ (4.8), $\mathrm{CaCl}_{2}$ (2), $\mathrm{MgSO}_{4}$ (1.2), $\mathrm{KH}_{2} \mathrm{PO}_{4}$ (1.25), $\mathrm{NaHCO}_{3}(25)$, D-glucose (10). The solution also contained $0.3 \mathrm{mM}$ pargyline, $0.13 \mathrm{mM}$ ascorbic acid, and $2.4 \mathrm{mM}$ EDTA. The tissues were incubated twice for $10 \mathrm{~min}$ each at $37^{\circ} \mathrm{C}$ in medium saturated with a mixture of $95 \%$ oxygen $/ 5 \%$ carbon dioxide. The third incubation was carried out in 
medium containing $25 \times 10^{-9} \mathrm{M}\left[{ }^{3} \mathrm{H}\right]$ serotonin (17$20 \mathrm{Ci} / \mathrm{mM}$, Amersham, England). We stopped the $\left[{ }^{3} \mathrm{H}\right]$ serotonin uptake by cooling the medium to $0{ }^{\circ} \mathrm{C}$. The materials were rinsed several times in pure, ice-cold medium, gently dried, weighed, and transferred to vials containing $1 \mathrm{~mL} 96 \%$ ethanol. The vials were then incubated for $18 \mathrm{~h}$ to extract the radioactively labeled compounds. Thereafter, the solution was dissolved in $10 \mathrm{~mL}$ of liquid scintillator and radioactivity-expressed as the number of scintillations $/ \mathrm{min}$ (cpm) per $1 \mathrm{mg}$ nervous tissuewas measured in a liquid scintillation counter (Intertechnique SL-30, France). Unspecific binding was evaluated by pre-incubating samples in medium containing an inhibitor of serotonin uptake, citalopram $\left(10^{-5} \mathrm{M}\right.$, Landbeck, Denmark), before the incubation in $\left[{ }^{3} \mathrm{H}\right]$ serotonin-containing medium. Specific uptake of the label was estimated as the difference between $\left[{ }^{3} \mathrm{H}\right]$ serotonin binding with and without pre-incubation with citalopram.

\section{Statistics}

Statistical analysis was carried out using descriptive statistics, the nonparametric Wilcoxon's test, and the Student's t-test for unpaired data.

\section{RESULTS}

\section{In vivo study}

Fetuses: at E21, most TH-immunoreactive neurons were located in the ventrolateral region of the arcuate nucleus, although a few were also found in the dorsomedial region (Fig. 1). The THimmunoreactive neurons, mainly unipolar or bipolar, were small. pCPA treatment of pregnant rats caused a decrease in the OD of TH-immunoreactive neurons of the arcuate nucleus in male and female fetuses, with no gender difference (Fig. 2).
Young rats: at $\mathrm{P} 35$, the number of $\mathrm{TH}$-immunoreactive neurons appeared to increase and were distributed predominantly in the dorsomedial region of the arcuate nucleus and, to a lesser degree, in the ventrolateral region. Decreased levels of THimmunoreactive material was found in neurons of the arcuate nucleus only in the male offspring of pCPA-treated pregnant rats (Fig. 3). Although the same tendency was characteristic of females, no significant difference was observed.

\section{In vitro study}

The appearance of $\mathrm{TH}$-immunoreactive neurons of the mediobasal hypothalamus in culture was similar to that in vivo. Such neurons were small, unipolar or bipolar, with a relatively large nucleus and scanty cytoplasm (Fig. 1). Rare multipolar TH-immunoreactive neurons were also observed. Serotonin-immunoreactive neurons were larger, with unbranched dendrite-like processes and highly arborized, axon-like processes. The presumed axons were identified according to the criteria of Konig et al. (1987): relative thinness, uniform caliber throughout the entire length, collaterals (if present), branching at angles close to $90^{\circ}$. All other processes were considered presumptive dendrites.

In single culture of the mediobasal hypothal-amus, the OD of TH-immunoreactive neurons in females exceeded that of males $(0.185 \pm 0.012$ in females vs. $0.14 \pm 0.015$ in males, $P<0.05$ ). The OD of serotonin neurons in single cultures of the raphe nucleus did not show sexual dimorphism (Fig. 4). Co-culture of mediobasal hypothalamus and raphe nucleus resulted in an increase in the OD of $\mathrm{TH}$ immunoreactive neurons in females and to a greater extent in males $(0.134 \pm 0.017$ males vs $0.05 \pm 0.014$ females, $\mathrm{P}<0.05$ ). Moreover, co-culture resulted in an increase in the OD of serotonin immunoreactive neurons in both males and females, without gender differences (Fig. 4). 


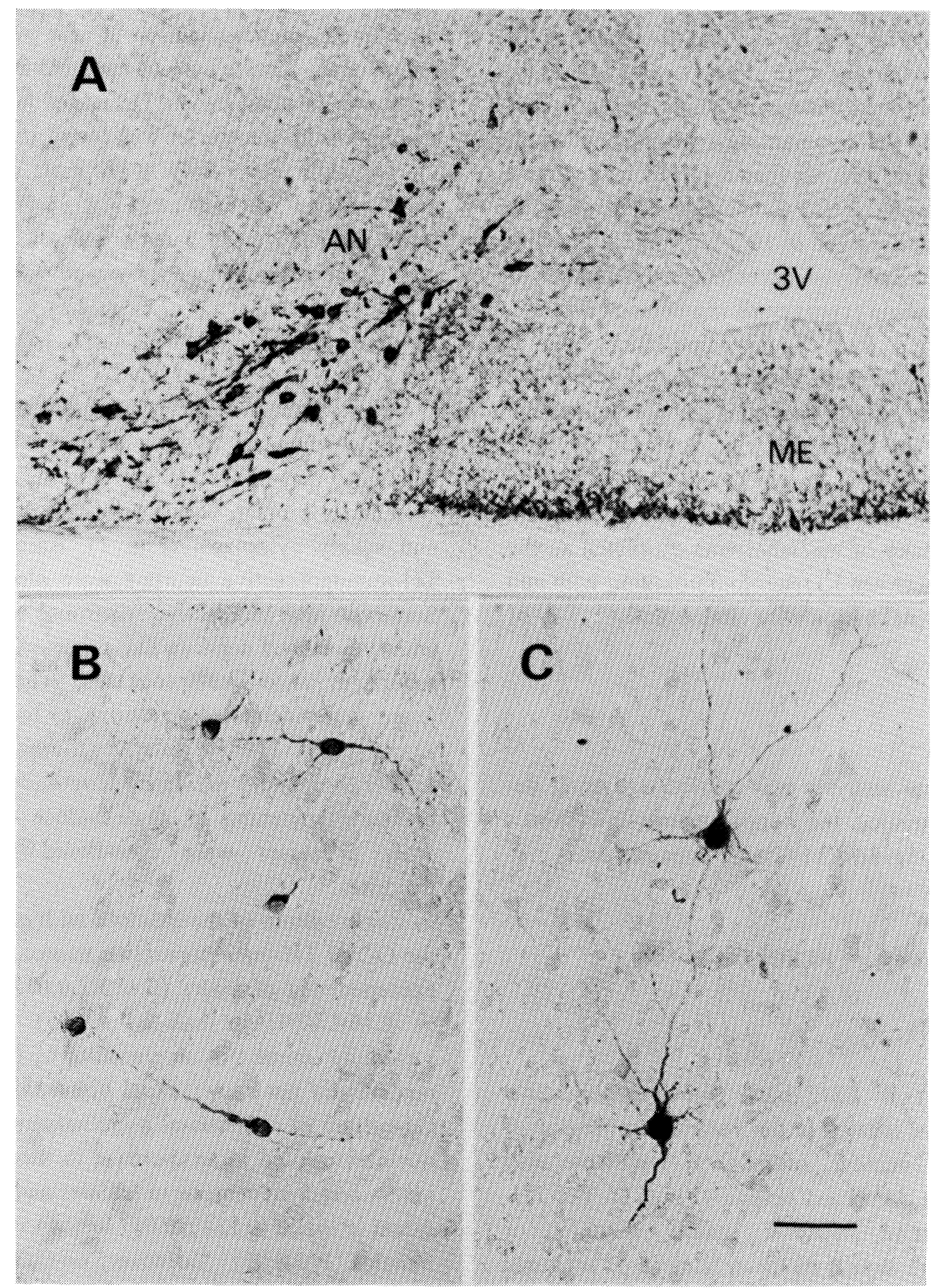

Fig. 1: Tyrosine hydroxylase-immunoreactive neurons in the arcuate nucleus at the $21^{\text {st }}$ embryonic day. Tyrosine hydroxylaseimmunoreactive neurons and serotonin-immunoreactive neurons in culture. $\mathrm{AN}$ - arcuate nucleus, $\mathrm{ME}$ - median eminence, $3 \mathrm{~V}-$ third ventricle. Scale bar $=50,43$, and $43 \mu \mathrm{m}$ for $\mathrm{A}, \mathrm{B}$ and $\mathrm{C}$, respectively. 

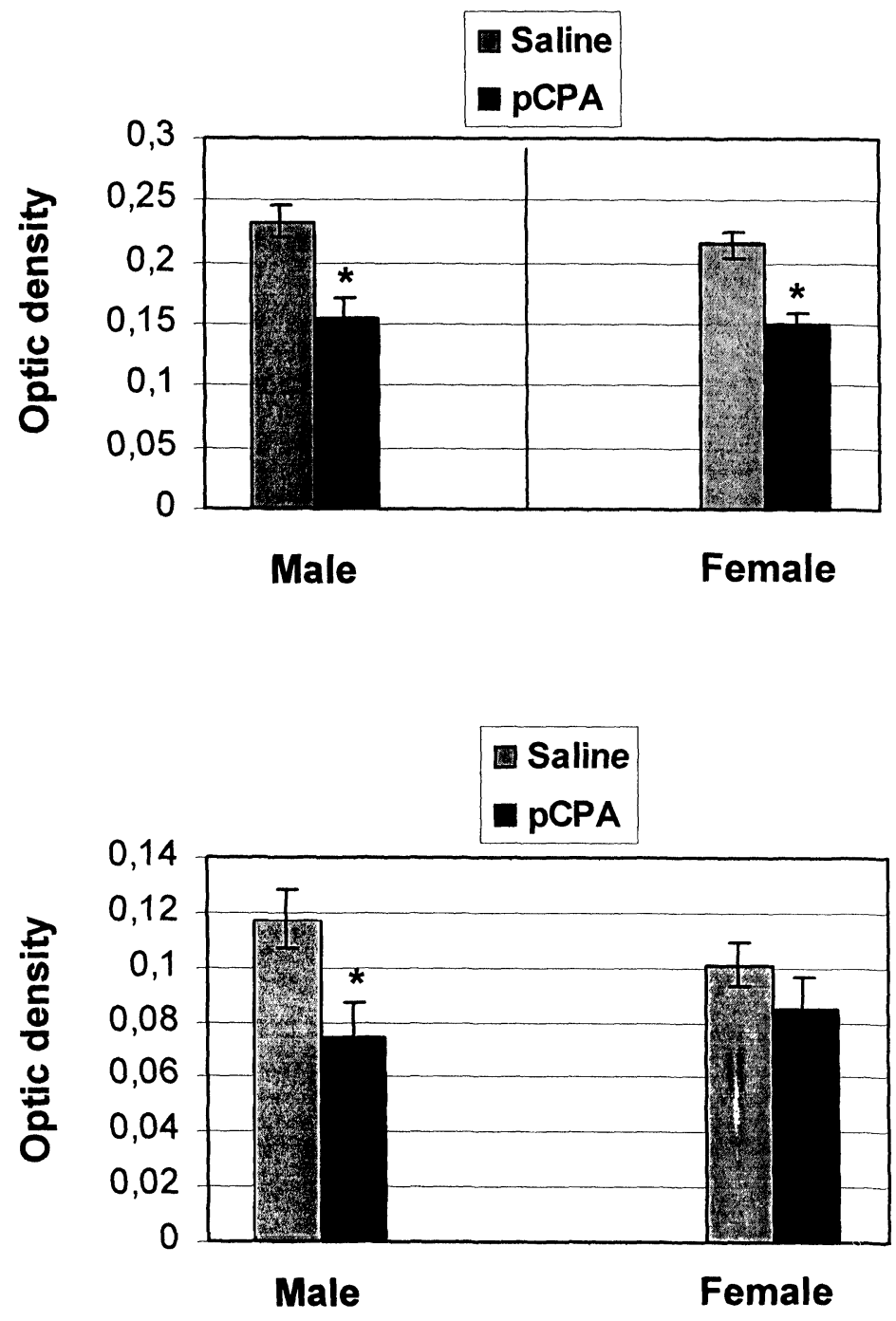

Fig. 2:Optical density of tyrosine hydroxylase-immunoreactive cell bodies in the arcuate nucleus.

Upper: Saline- and pCPA-treated rats, males and females, $21^{\text {st }}$ embryonic day. ${ }^{*} \mathrm{P}<0.05$.

Lower: Offspring, male and female, $35^{\text {th }}$ postnatal day after treatment of pregnant mothers with saline or pCPA. $\mathrm{P}<0.05$.

\section{DISCUSSION}

The pharmacological model of serotonin depletion in the fetal brain induced by intraperitoneal injections of pCPA to pregnant mothers was used in this and in prior studies for evaluating the influence of serotonin on the genesis and differentiation of target neurons (Lauder et al., 1981; Lauder, 1983; Ugrumov et al., 1994; Ugrumov, 1997). The specific effect of pCPA is related to a decrease of tryptophan hydroxylase activity and serotonin content in the fetal brain (Lauder et al., 1981, 1985; Lauder, 1983).

In contrast to PCPA concentrations used in 


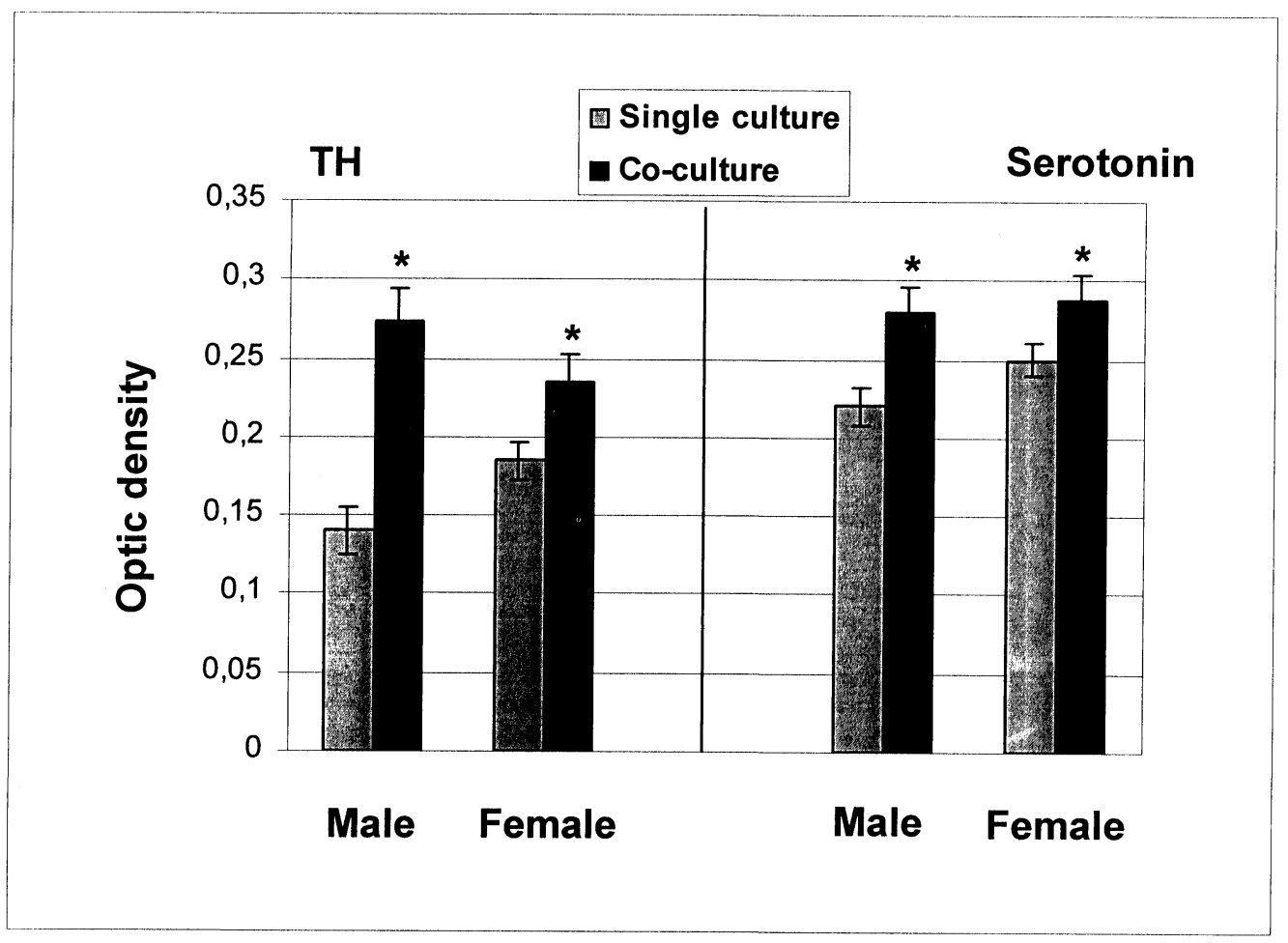

Fig. 3: Optical density of tyrosine hydroxylase (TH)-immunoreactive neurons and serotonin-immunoreactive neurons in single cultures of the mediobasal hypothalamus and the raphe nucleus, respectively, or in co-culture of the mediobasal hypothalamus and the raphe nucleus, taken in male and female rats at the $17^{\text {th }}$ fetal day and maintained for 7 days. ${ }^{*} \mathrm{P}<0.05$, comparison between single culture and co-culture.

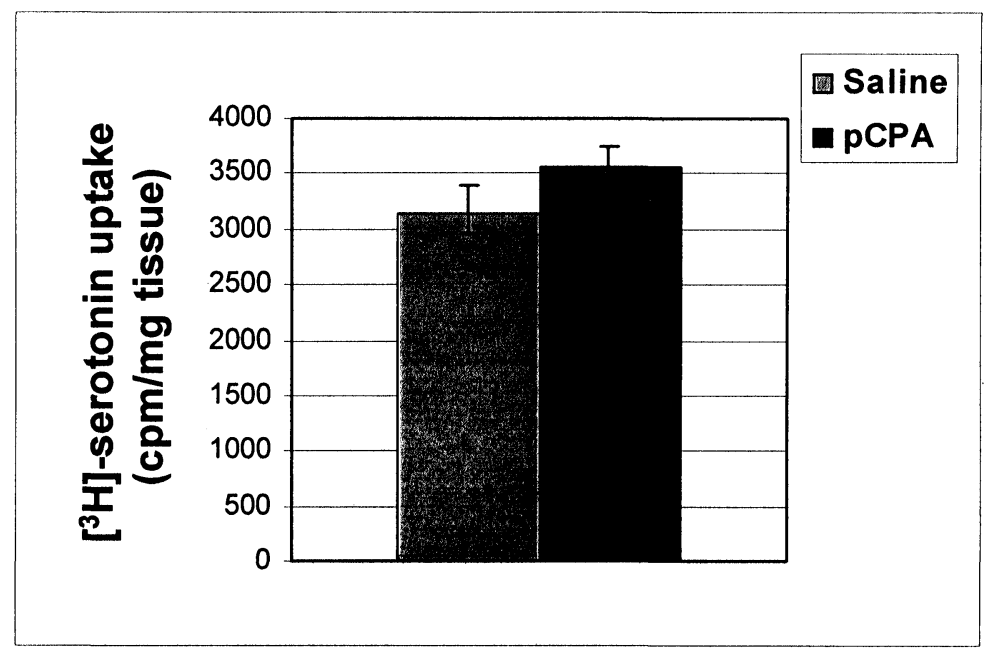

Fig. 4: Specific uptake of $\left[{ }^{3} \mathrm{H}\right]$-serotonin in the hypothalamus of rat fetuses (at the $21^{\text {st }}$ embryonic day) treated by saline or pCPA. 
earlier studies, (Koe \& Weissman, 1966; Lepetit et al., 1991; Tagliamonte et al., 1973), the at least 2.8fold lower concentration $(100 \mathrm{mg} / \mathrm{kg} \mathrm{b}$. wt.) used here was sufficient to provoke serotonin depletion, with a minimal risk of side effects (Lauder et al., 1981; Lauder, 1983). Finally, we used the pharmacological model of serotonin depletion to evaluate the immediate and delayed effects on TH expression in differentiating neurons of the arcuate nucleus.

In addition to the in vivo pharmacological model, we used in vitro co-cultures of the mediobasal hypothalamus and the raphe nucleus to determine whether serotonin afferents modify $\mathrm{TH}$ expression in differentiating neurons of the arcuate nucleus. The separation of arcuate nucleus and raphe nucleus neurons during the whole period of culture facilitated their identification and made possible the study of mutual regulatory effects under the absence of cell-cell contact.

To compare TH expression in the neurons of the arcuate nucleus in both experimental and control animals, we used a semi-quantitative image analysis, measuring the OD of the immunoreactive material correlated to the $\mathrm{TH}$ content. We emphasize (see Experimental Methods) that for the semiquantitative analysis, we processed male and female materials under standardized conditions (fixation, cutting, and immunostaining of sections mounted on the same slides). The validity of this approach was proved in early technical studies (Smolen, 1990) and later confirmed by concrete applications (Beltramo et al., 1994, 1997; Balan et al., 1996, 2000). Still, one should take into account that we could compare only the relative amounts of immunoreactive materials in males and females at each age studied, in vivo and in culture, separately.

In addition to the experimental approaches mentioned above, we used a biochemical isotopic technique to evaluate serotonin uptake by the developing hypothalamus and the adjacent neuroendocrine centers in chronic serotonin-depleted rats and in untreated control rats. This approach served to clarify whether the influence of serotonin in the arcuate nucleus of fetuses is limited to the target neurons, including TH-expressing neurons, or whether autoregulation of the local serotonin innervation also occurs. Indeed, serotonin uptake in the brain regions outside the raphe nucleus is considered an index of the density of serotonin fibers (Snyder et al., 1970; Sakurai et al., 1990).

\section{Serotonin influence on the tyrosine hydroxylase expression in vivo}

According to our semi-quantitative immunocytochemical study, chronic serotonin depletion occurring over the second half of the intrauterine development significantly decreased the $\mathrm{TH}$ content in differentiating neurons of the rat fetal arcuate nucleus at E21. In the meantime, the observation that serotonin uptake by hypothalamic tissue remained unchanged indicates that serotonin has no influence on the development of serotonin innervation. Taken together, the data suggest that serotonin stimulates $\mathrm{TH}$ expression in differentiating neurons of the arcuate nucleus. The morphogenetic action of serotonin on specific synthesis in differentiating target neurons appears to be cellspecific. In contrast to $\mathrm{TH}$ expression in the arcuate nucleus, vasoactive intestinal polypeptide gene expression in differentiating neurons of the suprachiasmatic nucleus is under serotonin inhibitory control during the same period of ontogenesis (Ugrumov et al., 1994).

Although the mechanism of the influence of serotonin on differentiating target neurons remains uncertain, apparently it is not transmitted via synaptic input because the major synaptogenesis in the arcuate nucleus occurs after birth (Koritszansky, 1981). Several investigators believe that before the onset of neurotransmission, serotonin exerts its action on the differentiating target neurons as a diffusive neurohumoral factor via serotonin recaptors that are expressed and become functionally 
active early in embryogenesis (Whitaker-Azmitia et al., 1987; Hellendall et al., 1993; WhitakerAzmitia et al., 1996; Wu et al., 1999). The 5-HT1 and 5-HT2 receptors appear to be the most probable candidates as they are involved in the inhibitory control of dopamine neurons of the arcuate nucleus in adults, providing the regulation of adenohypophysial prolactin secretion (Meltzer et al., 1983; Willoughby et al., 1988; Jorgensen et al., 1993). In addition to a direct action of serotonin on differentiating target neurons, an indirect action via glial cells cannot be excluded. Indeed, serotonin contributes to the regulation of secretion of glialderived neurotrophic/growth factors, which, in turn, stimulate neuron differentiation (WhitakerAzmitia et al., 1996). We approached this problem using cell culture (see below).

The decreased levels of TH observed in pCPAtreated fetuses persisted in young male rats (P35). The data suggest that serotonin provides a longlasting gender-specific, stimulatory influence on TH expression when acting on the differentiating neurons of the arcuate nucleus during the critical prenatal period. The molecular mechanism of the imprinting effect of serotonin has to be worked out in a future study.

\section{Influence of serotonin afferents on tyrosine hydroxylase expression in vitro}

According to the present study, in dissociated neurons of the arcuate nucleus, TH expression increases when co-cultured with dissociated neurons of the raphe nucleus, the only source of serotoninergic neurons in the brain. Apparently, the stimulatory effect was provided by neurohumoral factors originating in the raphe nucleus. The results of the in vitro study demonstrate that the influence of gliaderived neuro-trophic/growth factors can be excluded because the proliferation of glial cells was inhibited. In other words, TH expression in neurons of the arcuate nucleus is regulated by humoral factors that are synthesized by neurons of the raphe nucleus. Although such factors were not identified in this study, serotonin seems to be the most probable candidate, which agrees with our in vivo study and remains to be deduced in a future study.

Moreover, the results of our in vitro study revealed that the differentiating neurons of the arcuate nucleus and those of the raphe nucleus are mutually regulated. In fact, the significant increase in the serotonin content of the raphe nucleus neurons is due to their co-culture with the dissociated neurons of the arcuate nucleus. The data presented here are consistent with prior observations that the differentiation of serotonin neurons is influenced by their targets (Azmitia et al., 1990; Whitaker-Azmitia, 1991). In adults, the brain areas with dense serotonin innervation (hippocampus, cortex, caudate, olfactory bulb) stimulate the uptake of $\left[{ }^{3} \mathrm{H}\right]$ serotonin by neurons of the raphe nucleus in co-culture (WhitakerAzmitia, 1991).

\section{Sexual dimorphism in tyrosine hydroxylase expression and its regulation}

According to the results of our in vitro study, the $\mathrm{TH}$ content in neurons of the arcuate nucleus in single culture of females significantly exceeds that of males. This was also the case for neurons in the arcuate nucleus from E18 in vivo, the first age studied, onward (Balan et al., 2000). The data agree with prior observations showing that in vivo (Balan et al., 1996) and in the initial differentiation (outgrowth of processes) in culture (Reisert et al., 1989), the origin of hypothalamic TH-expressing neurons in females precedes that in males. Data from earlier studies (Reisert \& Pilgrim, 1991; Reisert et al., 1994; Ugrumov, 1994; Balan et al., 1996) suggest that sexual dimorphism in $\mathrm{TH}$ expression can be determined by gender-specific primary genetic programs of brain development or can be provoked by gender-specific neurohumoral 
factors that are different from testosterone or estradiol. Prolactin, a hormone of reproduction, might be considered a candidate for the factor contributing to the gender-specific development of TH-expressing neurons of the mediobasal hypothalamus (Phelps et al., 1993; Beyer et al., 1994).

In the in vivo study presented here, two observations can be discussed in relation to sexual dimorphism of differentiating TH-expressing neurons of the arcuate nucleus. In contrast to our results in an earlier in vivo study (Balan et al., 2000) and those of the present in vitro study in intact fetuses, we failed to find gender differences in the TH content of saline-injected control fetuses. According to prior data, the schedule of the genesis of serotonin target neurons and catecholamine metabolism in different brain regions can be modified also in fetuses by saline injections into their pregnant mothers (Moyer et al., 1978; Lauder et al., 1980). Although the mechanism of action remains uncertain, it is most probably related to an adrenal reaction to chronic stress that is provoked by regular saline injections.

According to another observation in our study, pCPA-induced serotonin depletion decreases the level of TH in males. Although the same tendency was a characteristic of females, the gender difference was not significant. From the data indirectly follows that testosterone somehow intensifies the long-term effect of serotonin depletion on the differentiating TH-expressing neurons. Thus we conclude that during prenatal ontogenesis, serotonin afferents provide a longterm stimulatory influence on TH expression in neurons of the rat arcuate nucleus.

\section{ACKNOWLEDGMENTS}

This work was supported by grants of the French Ministère de l'Enseignement Supérieur et de la Recherche (1994-1997), NATO (OUTR.CRG
970131), INTAS (IN-RU-1246) and the Russian Foundation for Basic Research (99-04-49134, 00-159784), PICS (98-04-22018).

\section{REFERENCES}

Aitken AR, Tork I. 1988. Early development of serotonin-containing neurons and pathways as seen in wholemount preparations of the fetal rat brain. J Comp Neurol 274: 32-47.

Arbogast LA, Voogt JL. 1991. Hyperprolactinemia increases and hypoprolactinemia decreases tyrosine hydroxylase mRNA levels in the arcuate nuclei, but not in the substantia nigra or zona incerta. Endocrinology 126: 997-1005.

Arbogast LA, Voogt JL. 1993. Progesterone reverses the estradiol-induced decrease in tyrosine hydroxylase mRNA levels in the arcuate nucleus. Neuroendocrinology 1993. 58: 501-510.

Arluison M, Dietl M, Thibault J. 1984. Ultrastructural morphology of dopaminergic nerve terminals and synapses in the striatum of the rat using tyrosine hydroxylase immunocytochemistry: a topographical study. Brain Res Bull 13: 169-185.

Azmitia E, Francfurt M, Davila M, Whitaker-Azmitia P, Zhou F. 1990. Plasticity of fetal and adult CNS serotoninergic neurons: Role of growth regulatory factors. In: Whitaker-Azmitia PM, Peroutka SJ, eds, The Neuropharmacology of Serotonin. A conference. New York City, July 10-13, 1989. Ann N Y Acad Sci 600: 243-268.

Balan I, Ugrumov M, Borisova N, Calas A, Pilgrim C, Reisert I et al. 1996. Birthdates of the tyrosine hydroxylase immunoreactive neurons in the hypothalamus of male and female rats. Neuroendocrinology 64: 405-411.

Balan I, Ugrumov M, Calas A, Mailly P, Krieger M, Thibault J. 2000. Tyrosine hydroxylase- and/or aromatic L-amino acid decarboxylase-expressing neurons in the mediobasal hypothalamus of perinatal rats: differentiation and sexual dimorphism. J Comp Neurol 425: 167-176

Bayer EA, Skutelsky E, Wilchek M. 1979. The avidinbiotin complex in affinity cytochemistry. Methods Enzymol 62: 308-135.

Beltramo M, Calas A, Chernigovskaya E, Borisova N, Polenova O, Tillet Y, et al. 1994. Postnatal devel- 
opment of the suprachiasmatic nucleus in the rat. Morpho-functional characteristics and time course of tyrosine hydroxylase immunopositive fibers. Neuroscience 63: 603-610.

Beltramo M, Calas A, Chernigovskaya E, Thibault J, Ugrumov M. 1979. Long lasting effect of catecholamine deficiency on the differentiating vasopressin neurons in the rat supraoptic nucleus. Neuroscience 79: 555-561.

Beyer C, Kolbinger W, Reisert I, Pilgrim C. 1994. Activation of cultured rat hypothalamic dopaminergic neurons by long-term but not by shortterm treatment with prolactin. Nuerosci Lett 180: 231-234.

Björklund A, Nobin C. 1973. Fluorescence histochemical and microspectrofluorometric mapping of dopamine and noradrenaline cell groups in the rat diencephalon. Brain Res 51: 193-205.

Daikoku S, Kawano H, Okamura I, Tokuzen M, Nagatsu I. 1986. Ontogenesis of immunoreactive tyrosine hydroxylase-containing neurons in rat hypothalamus. Dev Brain Res 28: 85-98.

Dahlström A, Fuxe K. 1964. Evidence for the existence of monoamine-containing neurons in the central nervous system. I. Demonstration of monoamines in the cell bodies of brainstem neurons. Acta Physiol Scand 62 suppl. 232: 1-155.

Friedman WJ, Dreyfus CF, McEwen BS, Black IB. 1989. Developmental regulation of tyrosine hydroxylase in the mediobasal hypothalamus. Dev Brain Res 48: 177-185.

Fuller RW, Clemens JA. 1981. Role of serotonin in the hypothalamic regulation of pituitary function. In: Haber B, Gabay S, Issidorides MR, Alivesatos SGA, eds, Serotonin: Current Aspects of Neurochemistry and Function. New York, NY, USA: Plenum Press; 431-444.

Fuxe K. 1964. Cellular localization of monoamines in the median eminence and infundibular stem of some mammals. Z Zellforsch 61: 719-724.

Halpern-Sebold LR, Margolis-Kazan H, Schreibman MP, Joh TH. 1985. Immunoreactive tyrosine hydroxylase in the brain and pituitary gland of the platyfish. Proc Soc Exp Biol Med 178(3): 486-489.

Hellendall RP, Shambra U, Liu J, Lauder JM. 1993. Prenatal expression of 5-HT1c and 5-HT2 receptors in the developing nervous system. Exp Neurol 120: 186-201.

Hong M, Li S, Pelletier G. 1995. Role of neuropeptide $\mathrm{Y}$ in the regulation of tyrosine hydroxylase mes- senger ribonucleic acid levels in the male rat arcuate nucleus as evaluated by in situ hybridization. J Neuroendocrinol 7: 25-28.

Hrabovszky E, Liposits Z. 1994. Galanin-containing axons synapse on tyrosine hydroxylase-immunoreactive neurons in the hypothalamic arcuate nucleus of the rat. Brain Res 652: 49-55.

Jorgensen H, Knigge U, Warberg J. 1993. Effect of selective serotonin receptor agonists on prolactin secretion in male rats. Neuroendocrinology 57: 401-407.

Kiss J, Halász B. 1986. Synaptic connections between serotoninergic axon terminal and tyrosine hydroxylase-immunoreactive neurons in the arcuate nucleus of the rat hypothalamus. A combination of electron microscopic autoradiography and immunocytochemistry. Brain Res 364: 284-294.

Koe K, Weissman A. 1966. P-Clorophenylalanine: a specific depletor of brain serotonin. J Pharmacol Exp Ther 154: 499-516.

Konig N, Han V, Lieth E, Lauder J. 1987. Effects of co-culture on the morphology of identified raphe and substantia nigra neurons from the embryonic rat brain. J Neurosci Res 17: 349-360.

Koritszansky S. 1981. Fetal and early postnatal cytoand synaptogenesis in the suprachiasmatic nucleus of the rat hypothalamus. Acta Morph Hung 29: 227-239.

Lauder JM, Wallace JA, Krebs H, Petrusz P. 1980. Serotonin as a timing mechanism in neuroembryogenesis. In: Brambilla F, Racagni G, de Wied D, eds, Progress in Psychoneuroendocrinology. Amsterdam, the Netherlands: Elsevier; 539-556.

Lauder JM, Sze PY, Krebs H. 1981. Maternal influences on tryptophan hydroxylase activity in embryonic rat brain. Dev Neurosci 4: 291-295.

Lauder JM. 1983. Hormonal and humoral influences on brain development. Psychoneuroendocrinology 8: 121-155.

Lauder JM, Towle AC, Patrick K, Henderson P, Krebs H. 1985. Decreased serotonin content of embryonic raphe neurons following maternal administration of p-chlorophenylalanine: a quantitative immunocytochemical study. Dev Brain Res 20: 107-114.

Lauder J. 1990. Ontogeny of serotoninergic system in the rat: serotonin as a developmental signal. In: Whitaker-Azmitia PM, Peroutka SJ, eds, The Neuropharmacology of Serotonin. A conference. New York City, July 10-13, 1989. Ann N Y Acad Sci 600: 297-315. 
Lepetit P, Touret M, Grange E, Gay N, Bobillier P. 1991. Decreased protein synthesis in hypothalamic nuclei following 1-5-hydroxytryptophan in intact and pchlorophenylalanine-pretreated rats. Neurosci Lett 122: 218-220.

Lidov HGW, Molliver ME. 1982. An immunohistochemical study of serotonin neuron development in the rat: ascending pathways and terminal fields. Brain Res Bull 8: 389-430.

Magoul R, Dubourg P, Kah O, Tramu G. 1994. Ultrastructural evidence for synaptic input of enkephalinergic nerve terminals to target neurons in the rat arcuate nucleus. Peptides 15: 883-892.

Melnikova V, Orosco M, Calas A, Sapronova A, Gainetdinov R, Delhaye-Bouchaud N, et al. 1999. Dopamine turnover in the mediobasal hypothalamus in rat fetuses. Neuroscience 88: 235-241.

Meltzer HY, Simonovic M, Gudelsky GA. 1983. Effects of pirenperone and ketanserin on rat prolactin secretion in vivo and in vitro. Eur $\mathrm{J}$ Pharmacol 92: 83-89.

Montange M, Calas A. 1988. Serotonin and Endocrinology-The Pituitary. In: Osborne NN, Hamo M, eds, Neural Serotonin. Chichester, UK: John Wiley \& Sons Ltd; 271-303.

Moore KE, Riegle GD, Demarest KT. Regulation of tuberoinfundibular dopaminergic neurons: prolactin and inhibitory neuronal influences. In: BenJonathan N, Bahr JM, Weiner RI, eds, Catecholamines as Hormone Regulators. New York, NY, USA: Raven Press, 1985; 31-48.

Moyer JA, Herrenkohl LR, Jacobowitz DM. 1978. Stress during pregnancy: effect on catecholamines in discrete brain regions of offspring as adults. Brain Res 144: 173-178.

Neill JD. Prolactin secretion and its control. 1988. In: Knobil E, Neill J, eds, The Physiology of Reproduction. New York, NY, USA: Raven Press; 1379-1390.

Phelps CJ, Carlson SW, Vaccarella MY, Felton SY. 1993. Development assessment of hypothalamic tuberoinfundibular dopamine in prolactin-deficient dwarf mice. Endocrinology 132: 2715-2722.

Phelps CJ, Carlson SV, Vaccarella MY. 1994. Hypothalamic dopaminergic neurons in prolactin deficient Ames dwarf mice: Localization and quantification of deficit by tyrosine hydroxylase immunocytochemistry. J Neuroendocrinol 6: 145-152.

Reisert I, Engele J, Pilgrim C. 1989. Early sexual differentiation of diencephalic dopaminergic neurons of the rat in vitro. Cell Tiss Res 255: 111-417.

Reisert I, Pilgrim C. 1991. Sexual differentiation of monoaminergic neurons-genetic or epigenetic? Trends Neurosci 14: 468-473.

Reisert I, Küppers E, Pilgrim C. 1994. Sexual differentiation of central catecholamine system. In: Smeets WJAJ, Reiner A, eds, Phylogeny and Development of Catecholamine Systems in the CNS of Vertebrates. Cambridge, UK: Cambridge University Press; 453-462.

Richards GE, Gluckman PD, Ball K, Mannelli SC, Kalamaras JA. 1990. Expanded ontogeny of neuro transmitters and their metabolites in the brains of fetal and newborn lambs. J Dev Physiol 14: 331 336.

Romero M I, Phelps CJ. 1993. Prolactin replacement during development prevents the dopaminergic deficit in hypothalamic arcuate nucleus in prolactindeficient Ames dwarf mice. Endocrinology 133: 1860-1870.

Sakurai E, Yamasaki S, Niwa H, Josson S, Hallmann J, Oreland L. 1990. Relation between serotonin and dopamine uptake rates, transmitter concentrations and monoamine oxydase activities in various regions of the rat brain. Biogenic Amines 7: 1-10.

Smolen AJ. 1990. Image analytic techniques for quantification of immunohistochemical staining in the nervous system. In: Conn PM, ed, Methods in Neurosciences. Quantitative and Qualitative Microscopy. San Diego: Academic Press; 208-229.

Snyder S, Kuhar M, Green A, Coyle J, Shaskan E. 1970. Uptake and subcellular localization of neurotransmitters in the brain. Int Rev Neurobiol 13: 128-143.

Steinbusch HW, Nieuwenhuys R. 1981. Localization of serotonin-like immunoreactivity in the central nervous system and pituitary of the rat, with special references to the innervation of the hypothalamus. Adv Exp Med Biol 133: 7-35.

Tagliamonte A, Tagliamonte P, Corsini G, Mereu G, Gessa G. 1973. Decreased conversion of tyrosine to catecholamines in the brain of rats treated with p-chlorophenylalanine. J Pharm Pharmacol 25: 101-103.

Tixier-Vidal A, Faivre-Bauman A. 1990. Use of hypothalamic cell culture to study role of diffusible factors in phenotypic expression of central nervous system neurons. In: Conn PM, ed, Methods in Neurosciences. New York, NY, USA: Academic Press; 355-369. 
Tramu G, Piller A, Leonardelli J. 1983. Serotonin axons of the ependima and circumventricular organs in the forebrain of the guinea pig. An immunocytochemical study. Cell Tiss Res 228: 297-311.

Ugrumov MV, Taxi J, Tixier-Vidal A, Thibault J, Mitskevich MS. 1989. Ontogenesis of tyrosine hydroxylase immunopositive structures in the rat hypothalamus. An atlas of neuronal cell bodies. Neuroscience 29: 135-156.

Ugrumov MV. 1994. Hypothalamic catecholaminergic systems in ontogenesis: development and functional significance. In: Smeets WJAJ, Reiner A, eds, Phylogeny and Development of Catecholamine Systems in the CNS of Vertebrates. Cambridge, UK: Cambridge University Press; 435-452.

Ugrumov MV, Trembleau A, Calas A. 1994. Altered vasoactive intestinal polypeptide gene expression in the fetal rat suprachiasmatic nucleus following prenatal serotonin deficiency. Int J Dev Neurosci 12: 143-149.

Ugrumov MV. 1997. Hypothalamic monoaminergic systems in ontogenesis: development and functional significance. Int J Dev Biol 41: 809-816.
Wallace JA, Lauder JM. 1983. Development of the serotoninergic system in rat embryo: an immunocytochemical study. Brain ResBull 10: 459-479.

Willoughby J, Menadus M, Liebelt H. 1988. Activation of 5-HT1 serotonin receptors in the medial basal hypothalamus stimulates prolactin secretion in the unanaesthetized rat. Neuroendocrinology 47: 83-87.

Whitaker-Azmitia P, Lauder J, Shemmer A, Azmitia E. 1987. Postnatal changes in serotonin receptors following prenatal alteration in serotonin levels: further evidence for functional fetal serotonin receptors. Dev Brain Res 33: 285-289.

Whitaker-Azmitia PM. 1991. Role of serotonin and other neurotransmitter receptors in brain development: basis for developmental pharmacology. Pharmacol Rev 43: 553-561.

Whitaker-Azmitia PM, Druse M, Walker P, Lauder JM. 1996. Serotonin as developmental signal. Behav Brain Res 73: 19-29.

Wu C, Dias P, Kumar S, Lauder JM, Singh S. 1999. Differential expression of serotonin 5-HT2 receptors during rat embryogenesis. Dev Neurosci 21: $22-28$ 

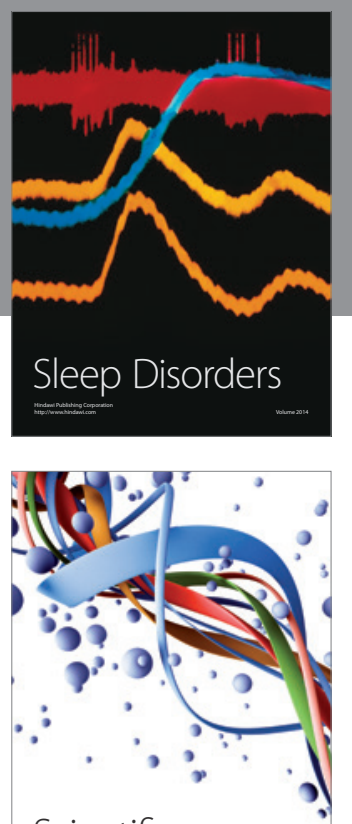

Scientifica
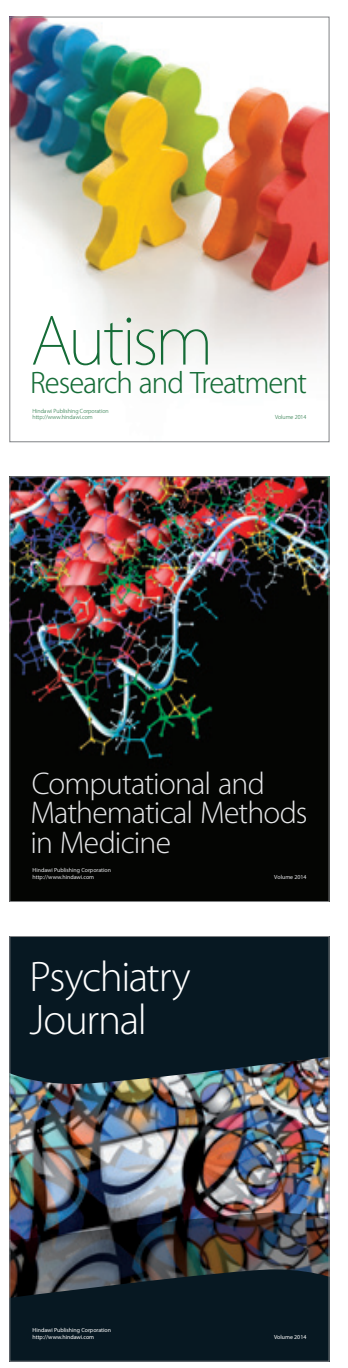
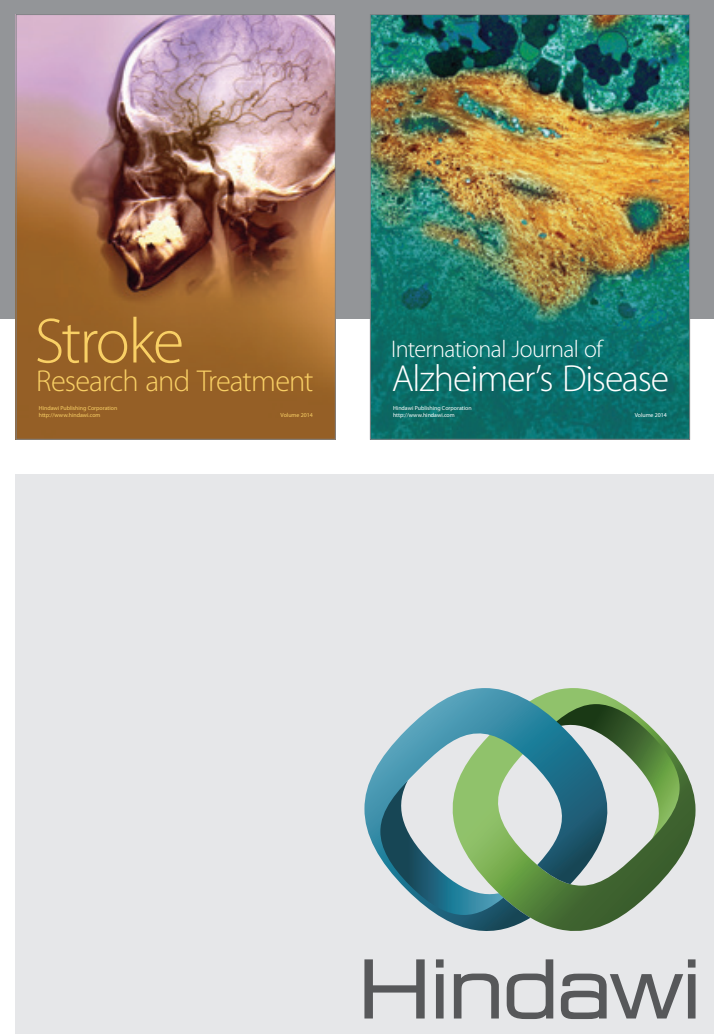

Submit your manuscripts at

http://www.hindawi.com
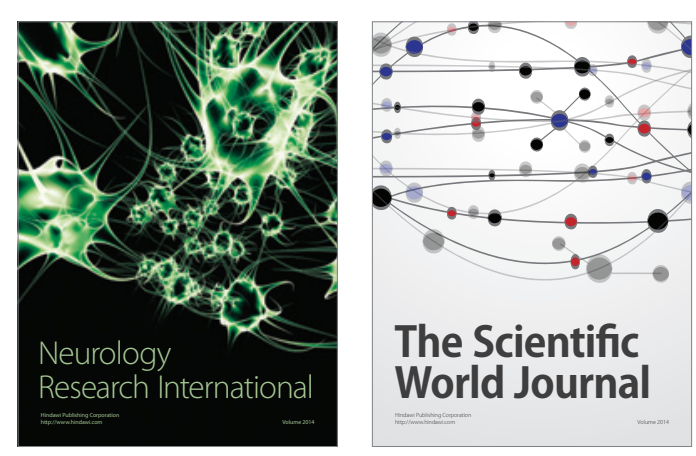

The Scientific World Journal

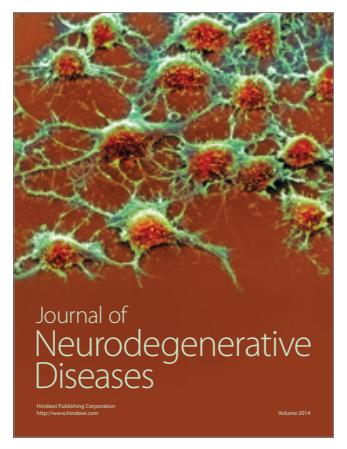

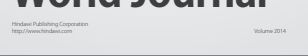

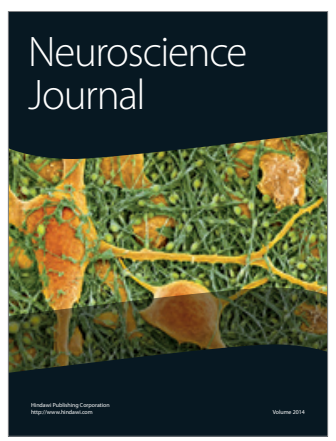

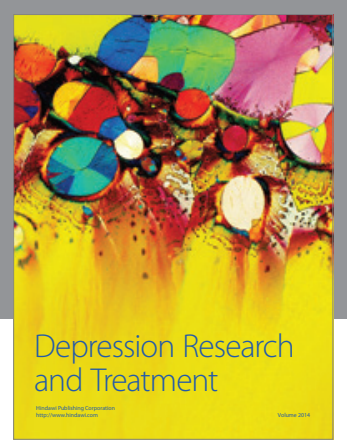
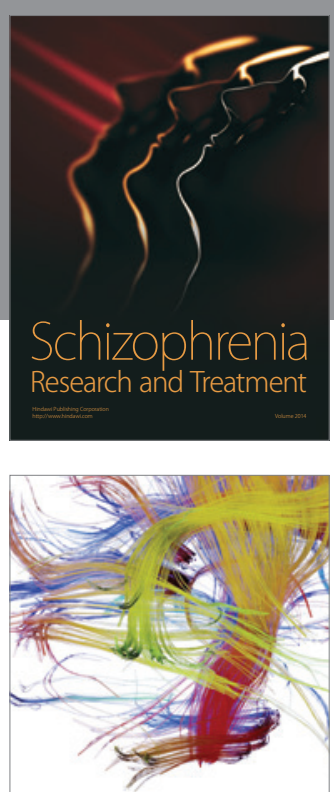

Brain Science

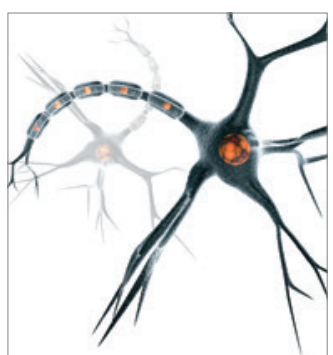

Neural Plasticity
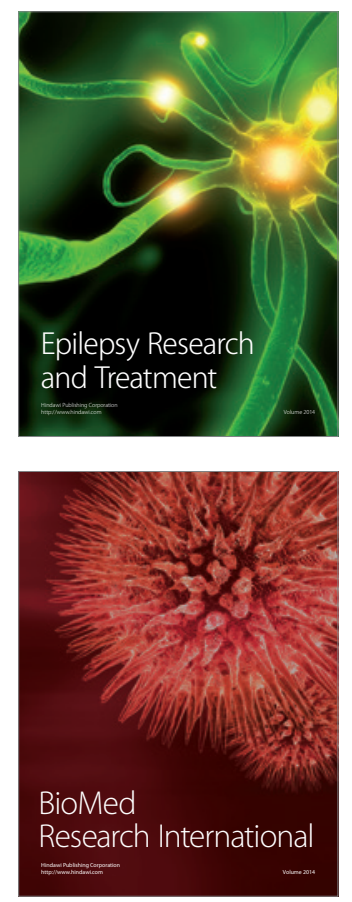

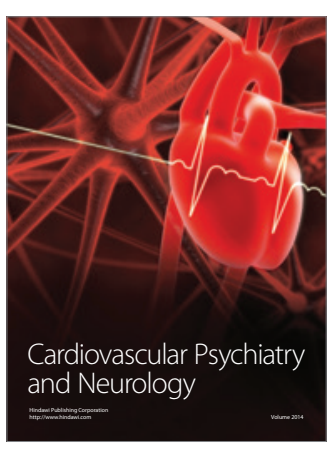

Parkinson's

Disease
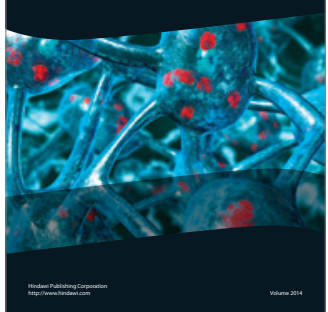